\title{
Prologue
}

\section{The WHO multinational study of vascular disease in diabetes}

After a presentation in Japan in the early 1970's on the excess of cardiovascular disease that we had observed in newly identified 'glucose intolerant' subjects in the Bedford population survey, I remarked to my host, Dr Eishi Miki of the University of Tokyo, on the relative lack of discussion after the talk. He politely explained that this was perhaps because coronary heart disease and ischaemic gangrene were uncommon in Japan, even in people with diabetes, in striking contrast with his observations at the Joslin Clinic in the United States. We discussed the possibility of a systematic and standardised clinical comparison of vascular disease in people with diabetes in London and Tokyo. A draft protocol for such a study was presented for comment and criticism to the European Diabetes Epidemiology Study Group. Many volunteered to join the comparative study as did colleagues from outside Europe. With the support of the Division of Non-Communicable Diseases at the World Health Organization (WHO) in Geneva, a final protocol, ultimately agreed and applied by 14 centres in 13 countries, became the WHO Multinational Study of Vascular Disease in Diabetes (WHO MSVDD).

WHO Geneva provided initial translations and facilities for data collection and analysis. The national patient cohorts were assembled with local funding. In 1974, a 3-day training meeting for active investigators was held by courtesy of the CIBA (now Novartis) Foundation in London. Questionnaires and examination procedures were centrally agreed but full centralisation for laboratory analyses was impeded by political barriers. Fasting plasma glucose measurement was feasible only in a subset of eight centres, of which five also measured triglycerides. A preliminary analysis of results, prepared by WHO statistician Dr Bernard Grab, was reviewed by investigators in 1977 and published with the study protocol in the newborn Diabetes Care [1-3]. It was from these publica- tions that the Chinese diabetic cohort (Paper 11 of this Supplement) was independently assembled using the same protocol. The definitive WHO MSVDD prevalence analysis appeared in Diabetologia in 1985 [4], by which time 10 of the 14 centres were already engaged in the morbidity and mortality follow-up study. These results, the incidence of microvascular and macrovascular disease outcomes, their relation to baseline characteristics and further analyses of mortality data (other aspects of which have appeared elsewhere [5-16]), are presented in this Supplement.

Collection and analysis of morbidity data was transferred to the University of Oklahoma in 1979, under the direction of Prof. Kelly M. West and, after his untimely death, of Prof. Elisa Lee. The completion of the morbidity follow-up study is a tribute to the perseverance and hard work of Professor Lee and her colleagues as well as to the multinational investigators. A special debt of gratitude is owed to the United States National Institute of Diabetes, Digestive and Kidney Diseases for support which made full collection, analysis and publication possible and in particular to Dr Maureen Harris whose interest and encouragement have been unfailing. Collection and statistical analysis of mortality data was co-ordinated by Prof. John Fuller and his colleagues at the Department of Epidemiology and Public Health, University College, London. Maintaining motivation and momentum in a group of investigators so widely spread across the globe and over the course of so many years was a major achievement.

The study was unavoidably lacking in a number of respects. Glycated haemoglobin had not yet been recognised as a powerful measure of glycaemic control. That the single fasting blood glucose, measured at baseline in 8 of the 10 follow-up centres, performed so well as a 'predictive' variate is a clear indication of the importance of glycaemic control. Facilities 
and experience for retinal photography and central reading, now the 'gold standard' for epidemiological ascertainments of diabetic retinopathy, were limited or non-existent in several centres thus the traditional method of direct ophthalmoscopy through dilated pupils was used, supported by a detailed protocol for ascertainment. Nonetheless, this study was the first to attempt application of international standardisation of methods to the clinical epidemiology of diabetes to improve comparability between centres; and it spurred the evolution of better methods now in use. Definitions and categories of abnormality used for the WHO MSVDD were, nevertheless, robust and faithfully applied by those who accepted the disciplines of the study protocol.

Despite shortcomings, the WHO MSVDD provides very suggestive evidence of variation in the impact of diabetes on the health and life of disparate groups of people with diabetes. One can only speculate on how much of this variability is attributable to differing genetic constitution and how much to its interactions with diverse environmental milieux. A great deal is likely to have been due to major regional differences in diabetes management. There is now compelling evidence that the burden of diabetes and its complications can be mitigated by improving the quality of care, often achieved by doing simple things well. It is hoped that this study, though long in gestation, will contribute to the better understanding of the impact of an increasingly common disease and also constitute a baseline against which the results of improved care can be measured.

Harry Keen for the Multinational Group of Investigators

\section{References}

1. Jarrett RJ, Keen H, Grabauskas V (1979) The WHO Multinational Study of Vascular Disease in Diabetes: 1 General description. Diabetes Care 2: 175-186

2. Keen H, Jarrett RJ (1979) The WHO Multinational Study of Vascular Disease in Diabetes: 2. Macrovascular disease prevalence. Diabetes Care 2: 187-195

3. Jarrett RJ, Keen H (1979) The WHO Multinational Study of Vascular Disease in Diabetes: 3. Microvascular disease. Diabetes Care 2: 196-201
4. Diabetes Drafting Group (1985) Prevalence of small vessel and large vessel disease in diabetic patients from 14 centres. The WHO Multinational Study of Vascular Disease in Diabetics. Diabetologia 28: 615-640

5. Fuller JH, Head J, WHO Multinational Study Group (1989) Blood pressure, proteinuria and their relationship with circulatory mortality: the WHO multinational study of vascular disease in diabetes. Diabetes Metab 15: 273-277

6. Head J, Fuller JH (1990) International variations in mortality among diabetic patients: the WHO multinational study of vascular disease in diabetics. Diabetologia 33: 477-481

7. Fuller JH, Stevens LK (1991) Epidemiology of hypertension in diabetic patients and implications for treatment. Diabetes Care 14 [Suppl 4]: 8-12

8. Chaturvedi N, Stevens LK, Fuller JH, WHO Multinational Study Group (1995) Mortality and morbidity associated with body weight in people with IDDM. The WHO Multinational Study of Vascular Disease in Diabetes. Diabetes Care 18: 761-765

9. Chaturvedi N, Fuller JH, The WHO Multinational Study Group (1995) Mortality risk by body weight and weight change in people with NIDDM. The WHO Multinational Study of Vascular Disease in Diabetes. Diabetes Care 18: 766-774

10. Stephenson JM, Kenny S, Stevens LK, Fuller JH, Lee E, WHO Multinational Study Group (1995) Proteinuria and mortality in diabetes: the WHO Multinational Study of Vascular Disease in Diabetes. Diabet Med 12: 149-155

11. Fuller JH, Stevens LK, Wang SL (1996) International variations in cardiovascular mortality associated with diabetes mellitus; the WHO Multinational Study of Vascular Disease in Diabetes. Ann Med 28: 319-322

12. Fuller JH, Stevens LK, Wang S (1996) Epidemiology of hypertension in diabetic patients. J Cardiovasc Pharmacol 28 [Suppl 28]: S1-S5

13. Wang S, Head J, Stevens L, Fuller JH, WHO Multinational Study Group (1996) Excess mortality and its relation to hypertension and proteinuria in diabetic patients: the WHO Multinational Study of Vascular Disease in Diabetes. Diabetes Care 19: 305-312

14. Chaturvedi N, Stevens L, Fuller JH, WHO Multinational Study Group (1997) Which features of smoking determine mortality risk in former cigarette smokers with diabetes? Diabetes Care 20: 1266-1272

15. West KM, Ahuja MMS, Bennett PH et al. (1982) Interrelationships of microangiopathy, plasma glucose and other risk factors in 3583 diabetic patients: A multinational study. Diabetologia 22: 412-420

16. West KM, Ahuja MMS, Bennett PH et al. (1983) The role of circulating glucose and triglyceride concentrations and their interactions with other "risk factors" as determinants of arterial disease in nine diabetic population samples from the WHO Multinational Study. Diabetes Care 6: 361-369 